\title{
Exploration and Practice of Volume Fracturing Technology of Shale Oil in Dagang Oilfield
}

\author{
Yin Shun-li ${ }^{*}$, Zhuang Tian-lin ${ }^{1}$, Yang Li-yong ${ }^{1}$, Jia Yun-peng ${ }^{1}$, Liu Xue-wei ${ }^{1}$, Liu Yu ${ }^{1}$, Yan Yu ${ }^{1}$ \\ 1 (PetroChina Dagang Oilfield Company, Tianjin, 300280, China) \\ Introduction:Yin Shun-li(1990-),Male, Master degree, Engineer,Mainly engaged in fracturing technology research. \\ Company:.Petroleum Engineering Research Institute of Dagang Oilfield, PetroChina
}

\begin{abstract}
Based on the geological characteristics of the shale oil in the Kong 2 Member of the Cangdong Sag, Dagang Oilfield,and a large number of core experiments and numerical simulations, the displacement and single-stage liquid volume of the fracturing construction were simulated and optimized; in the stratigraphic shale and stratified mixed shale, the reverse mixing mode is adopted, that is, the gel is used for the rock-breaking seam, and then the low-concentration low-damage fracturing fluid system is used to form the complex seam net. Finally, the high-conductivity-producing area near the well is formed by the addition of sand and gel, forming a personalized horizontal well-cut volume fracturing technology in Dagang Oilfield. The application of this technology in shale oil shows that the output of horizontal well is stable after dense cutting volume fracturing, and industrial development can be realized. Microseismic and stable electric field monitoring confirmed the formation of complex network cracks, and achieved significant yield-increasing effects, providing a reference for the efficient exploration and development of China's continental shale oil.
\end{abstract}

\section{Introduction}

In the 21 st century, the exploration and development of unconventional resources such as shale gas and shale oil have become an important part of global oil and gas production, which has deeply reshaped the global energy landscape and geopolitics. Unconventional oil and gas production in the United States has accounted for $70 \%$, promoting the implementation of the "energy independence" strategy of the United States. Shale oil exploration and development technology in China started late, and the development characteristics and geological conditions of shale oil in various basins are quite different, so the effective development technology mode is very limited. The eastern rift basin has become the key area of continental shale oil exploration and development in China ${ }^{[1]}$. The formation conditions of shale oil in the second member of Kongyuan formation in Cangdong sag of Dagang are favorable, and the shale oil resource is 6.8 $\times 108 \mathrm{t}$, which has great exploration and development potential. But the sedimentary structure background is complex, the source reservoir structure model is changeable, the reservoir physical property is poor, the heterogeneity is strong, and the fracturing high and stable production ability is poor ${ }^{[2]}$. In order to realize the effective development of shale oil, Dagang Oilfield has drilled two shale oil horizontal wells and carried out the exploration of volume fracturing technology for shale oil horizontal wells, forming key fracturing technologies such as low damage composite fracturing fluid system, low cost and high efficiency support technology, dense cutting volume fracturing technology, personalized transformation mode of different source and reservoir formations, and geological engineering integrated perforation optimization technology, Improve the complexity and supporting effect of fractures in each section of horizontal wells, and realize the volume transformation of shale oil reservoir.

\section{Geological characteristics of Kong 2 formation shale oil}

The Kongdian Formation in Cangdong sag was in Lake flooding stage, and the shale series in the middle of the closed lake basin developed. According to the source reservoir combination model, it can be divided into three types: laminated felsic shale, laminated mixed shale and massive limestone facies ${ }^{[3]}$.

The shale oil rocks of Kong 2 member in Cangdong sag are mainly composed of clay and silt grade sediments with particle size less than 62.5um. The mineral composition mainly includes feldspar quartz, carbonate rock and clay. The pore throat is mainly $20-700 \mathrm{~nm}$, with an average of $520 \mathrm{~nm}$, porosity of $1.0 \% \sim 12.0 \%$, and permeability of $0.02 \sim 1.0 \mathrm{md}$. The density of crude oil is $0.86 \sim 0.887 \mathrm{~g} / \mathrm{cm} 3$, and the average viscosity of crude oil at $80^{\circ} \mathrm{Cis} 19.3 \mathrm{mpa} \cdot \mathrm{s}$. The formation temperature is 140-150 ${ }^{\circ}$ Cand the pressure coefficient is 
0.96-1.27 $7^{[4]}$.Well G108-8 has been coring $495 \mathrm{~m}$ continuously in kong 2 formation. Core description and thin section observation show that there are 2432 layers with thickness less than $1 \mathrm{~cm}$, accounting for $68 \%$. It has typical shale fabric characteristics. Imaging logging of this well shows that there are 6 natural fractures in $40 \mathrm{~m}$ shale formation, with low density of natural fractures.

Rock mechanics tests show that the static Young's modulus of Kong 2 formation is $10-43.7 \mathrm{GPa}$ and Poisson's ratio is $0.11-0.417$. The maximum horizontal principal stress is $72.7-81.0 \mathrm{MPa}$, the minimum horizontal principal stress is $48.5-58.5 \mathrm{MPa}$, and the difference of horizontal principal stress is $21.0-25.4 \mathrm{MPa}$, with an average of $22.9 \mathrm{MPa}$.Triaxial test of $\operatorname{rock}^{[5][6]}$ 、 The microseismic monitoring and stable electric field monitoring show that the fracture form of shale oil vertical well is simple, and the reconstruction volume is limited, As shown in Figures 1 and 2.

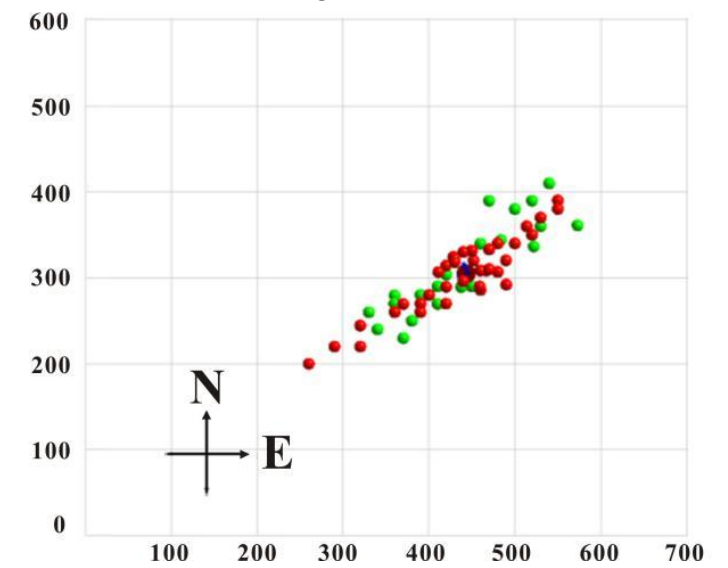

Fig. 1 Fracture direction monitored by microseismic in well G108-8

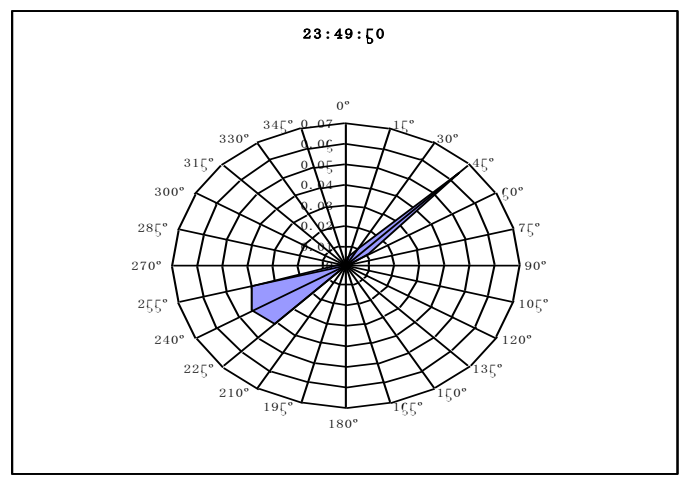

Fig. 2 Fracture direction monitoring by stable electric field in well G108-8

\section{Volume fracturing technology of shale oil in Kong 2 formation}

GD1701H and GD1702H are two shale oil horizontal wells in Kong 2 member of Cangdong sag. The completion drilling depth of GD1701H well is $5465.49 \mathrm{~m}$, the vertical depth is $3851.5 \mathrm{~m}$, and the horizontal section is $1474 \mathrm{~m}$; the completion drilling depth of GD1702H well is $5298 \mathrm{~m}$, the vertical depth is $3930 \mathrm{~m}$, and the horizontal section is $1329.88 \mathrm{~m}$. The reservoir is buried deep and the stress is high, which leads to high construction pressure. In addition, the fractures near the wellbore are complex, which makes it difficult to construct. The reservoir temperature of well GD1701H and GD1702H is high, and the scale of single section transformation of horizontal well is large, and the requirements for temperature and shear resistance of fracturing fluid are high. There are many sets of different types of reservoirs in Kong 2 member of Guandong tight oil field, which requires the improvement process. The reservoir has poor physical properties, high crude oil viscosity, low oil ratio of dissolved gas and low oil saturation, which makes it difficult to improve the production of the well

\subsection{Close cut volume fracturing technology}

Shale oil reservoir is dense and brittle, so it is necessary to use slippery water with large displacement to improve fracture complexity ${ }^{[7]}$. According to the numerical simulation to optimize the optimal conductivity of equivalent fracture, the optimization method of conductivity of complex fracture network is established by using the hydropower similarity principle ${ }^{[8]}$. Main fracture near wellbore is supported by $30 / 50$ mesh and 40/70 mesh composite ceramsite, main fracture near wellbore is supported by $30 / 50$ mesh ceramsite; secondary fracture is supported by $40 / 70$ mesh ceramsite; micro fracture is supported by $70 / 140$ mesh quartz sand and rock rough surface. The biggest difference between shale oil and conventional low-permeability reservoirs is that there is a strong start-up pressure gradient. For shale oil reservoirs, the start-up pressure gradient is high. The size of the start-up pressure gradient directly determines the available range of the reservoir. Even if the movable range of fracturing is small and the shale reservoir has a high fracturing gradient, the core of "fracture-controlled reserves" fracturing is to minimize the area of non-flowing areas, reduce the fluid seepage distance in the matrix, and increase the matrix. The oil and gas in the medium drive the pressure gradient, which greatly increases the available reserves. In the Guandong shale oil reservoir, due to low mobility and high starting pressure gradient, increasing the number of fractures significantly improves the improvement effect, as shown in Figure 3.

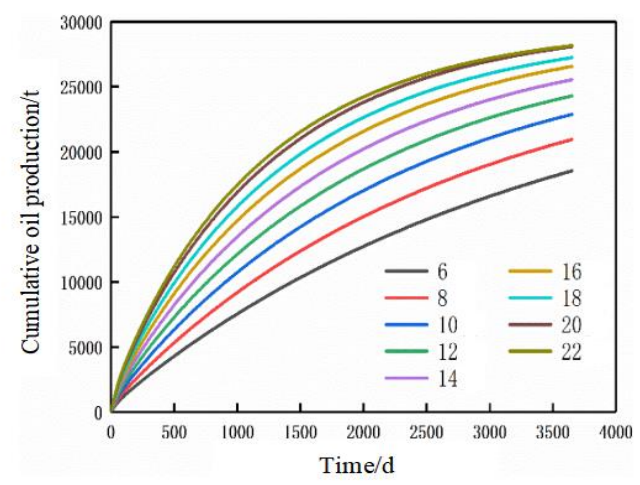

Fig.3 The relationship between the number of transformation stages and accumulative production 


\subsection{Personalized transformation model of different source and storage fabric models}

Foreign physical model experiments show that the height direction of hydraulic fractures is controlled by bedding. When there are longitudinal lithological non-averages and bedding planes, the height of the fractures is complicated, the extension of the fracture height is limited, and the hydraulic fractures extend along the inside of the layer. In order to increase the vertical expansion of fracture heights, laminar felsic shale and laminar mixed shale adopt inverse mixing transformation mode. The jelly is first used to break the rock and make the joints, then the slippery water is used to form a complex fracture network, and finally the jelly is added to form a high conductivity area near the well. For the massive lime dolomite model, the thickness of a single layer of the reservoir is greater than $2 \mathrm{~m}$, which is mainly characterized by shale and dolomite. In order to avoid excessive growth of the fracture height at the fracture initiation stage, the combined fracturing model is adopted, use the slick water to open the cracks with a large displacement to form complex cracks, and then use the jelly to carry sand to form an area with high conductivity near the well.

\subsection{Key fracturing technology for geo-engineering integration optimization process}

Zhao Xianzheng, Zhou Lihong and others have established a fracture network index model based on rock brittleness factor, natural fracture factor, and in-situ

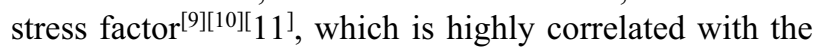
fracture morphology of the shale oil in Kong 2. The index is $0.3-0.4$, the fracture complexity is average; the fracture network index is greater than 0.4 , the fracture complexity is higher. Reservoirs with a fracture network index greater than 0.35 are easy to form complex fracture networks, and the fracture spacing is optimized to $15-20 \mathrm{~m}$; for reservoirs with a fracture network index less than 0.4 , the fracture spacing is optimized to be between $10-15 \mathrm{~m}$.

\subsection{Optimization of process parameters}

\subsubsection{Optimal construction displacement}

According to the fluid volume of $2000 \mathrm{~m} 3$ and the displacement of 4, 6, 8, 10, 12 and $14 \mathrm{~m}^{3} / \mathrm{min}$ respectively, the fracturing effect is simulated. The larger the construction displacement, the greater the net pressure of the fracture and the larger the range of fracture expansion. When the displacement is less than $8 \mathrm{~m}^{3} / \mathrm{min}$, the crack propagation is limited and the control reserve range is small. Therefore, the preferred displacement of the comprehensive casing strength and fracturing equipment capacity is $12-14 \mathrm{~m}^{3} / \mathrm{min}$, as shown in Figure 4 .
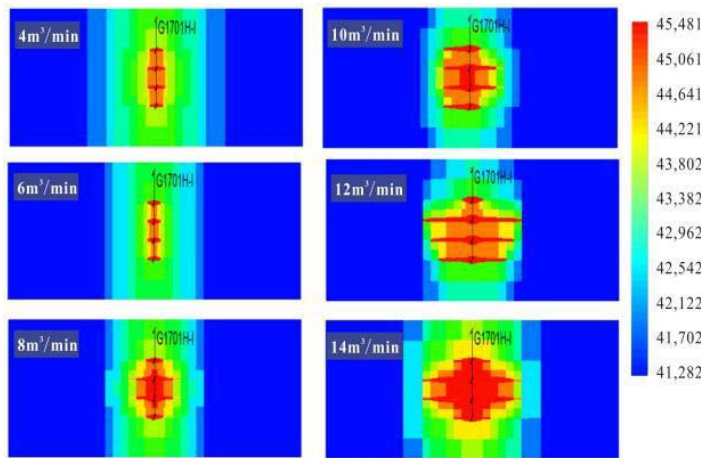

Fig. 4 Simulation of Crack Propagation in Different Construction Displacement

\subsubsection{Optimization of construction fluid volume}

The fracturing effect is simulated according to the displacement of $12 \mathrm{~m}^{3} / \mathrm{min}$ and the fluid volume of 600 , $800,1200,1600,2000$ and $2400 \mathrm{~m}^{3}$. The larger the total fluid volume, the higher the net pressure in the fracture after fracturing, and the larger the fracture propagation range. When the fracturing fluid volume exceeds $2000 \mathrm{~m}^{3}$, the fracture extension degree weakens, so the fluid volume per section is optimized to $2000 \mathrm{~m}^{3}$, as shown in Figure5.
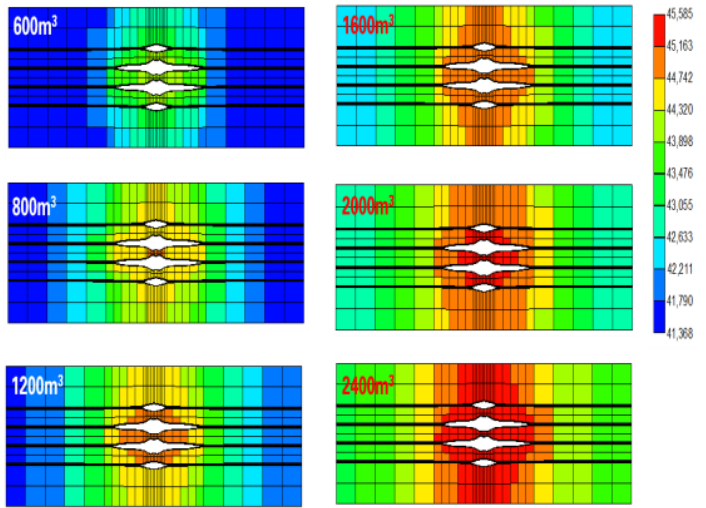

Fig. 5 Fracture morphology after fracturing with different liquid volume

\section{Field application and effect evaluation}

The two wells of GD1701H and GD1702H adopt horizontal well subdivision cutting volume fracturing technology. The construction parameters are shown in Table 1. A total of 75,388 cubic meters of fracturing fluid and 2731 cubic meters of sand are used. The production situation is shown in Figure 6.

Table 1 Basic parameters of shale oil horizontal well fracturing

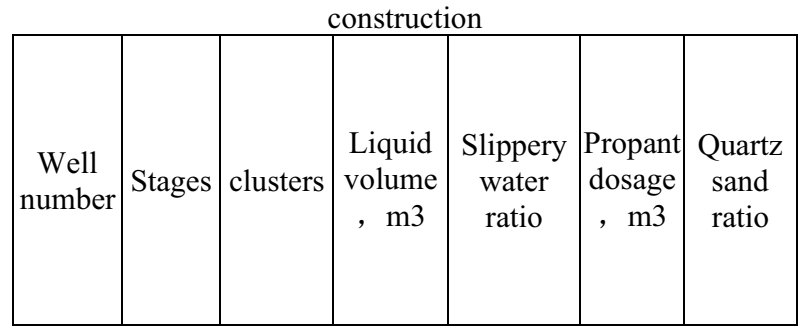




\begin{tabular}{|c|c|c|c|c|c|c|}
\hline $\begin{array}{c}\text { GD170 } \\
1 \mathrm{H}\end{array}$ & 16 & 54 & 34089 & $80 \%$ & 1387 & $30 \%$ \\
\hline $\begin{array}{c}\text { GD170 } \\
2 \mathrm{H}\end{array}$ & 21 & 66 & 40678 & $81.70 \%$ & 1343 & $30.60 \%$ \\
\hline
\end{tabular}

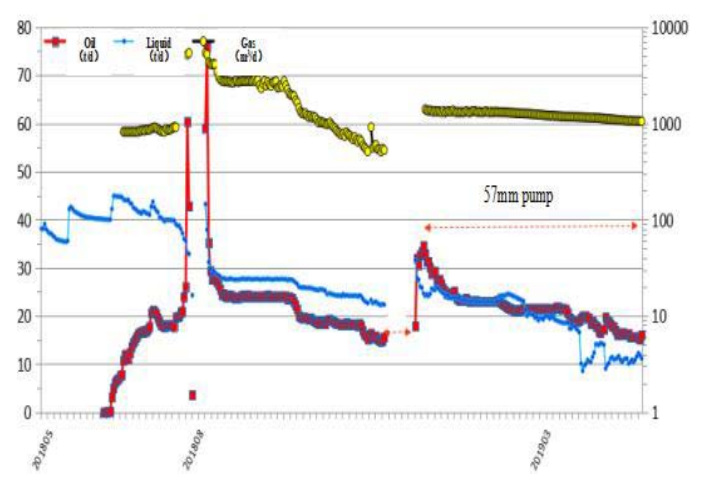

Fig. 6 GD1701 production curve

Microseismic monitoring GD1701H: the fracture length is $1230 \mathrm{~m}$, the fracture width is $480 \mathrm{~m}$, the fracture height is $120 \mathrm{~m}$, and the volume of the fracture control zone is $0.07 \mathrm{~km} 3$. The volume of the shale oil horizontal well has been reconstructed, as shown in Figure 7. Stable electric field fracture monitoring The fracture width of Well GD1701H is $8 \sim 32 \mathrm{~m}$, and the fracture length is 91 258m. The perforation clusters have achieved fracture propagation, as shown in Figure 8.

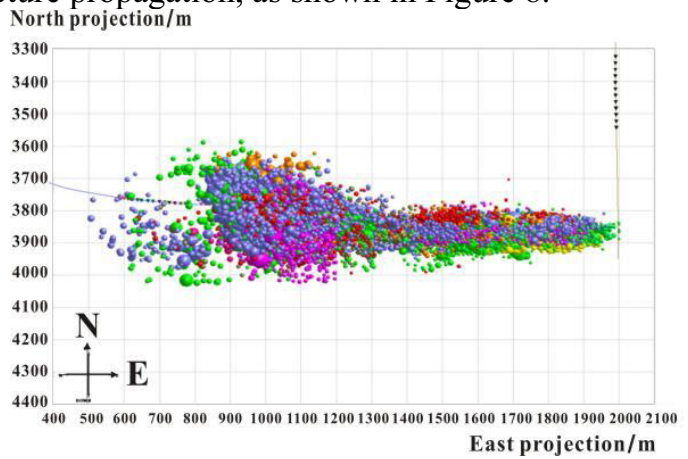

Fig. 7 GD1701H microseismic monitoring map

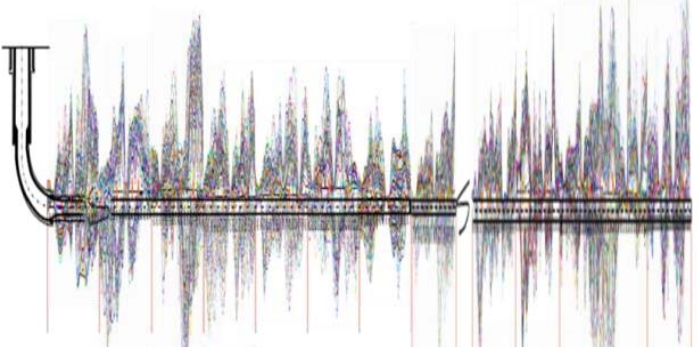

Fig. 8 GD1701H stable electric field monitoring chart

\section{Conclusion and understanding}

(1) The dense-cut volume fracturing technology for inverse mixing horizontal wells has improved the fracture complexity of the continental shale oil horizontal wells in Kong2, increased the volume of horizontal well reconstruction, and improved the effect of horizontal well fracturing.

(2) Based on the fracture network index model and the results of numerical simulation, it can be seen that the larger the discharge of continental shale oil in the second member of Kong, the greater the net pressure of fractures and the larger the range of fracture expansion, when the displacement is less than $8 \mathrm{~m} 3 / \mathrm{min}$ When the fracture expansion is limited, the control reserve range is small; the larger the total fluid volume of a single fracturing stage, the higher the net pressure in the fracture after fracturing, and the larger the fracture expansion range. When the fracturing fluid volume exceeds $2000 \mathrm{~m}^{3}$, the fracture expansion degree Weaken.

( 3 ) Simultaneous application of microseismic monitoring and stable electric field monitoring technologies can reflect the microseismic event area caused by stress and strain, the scope of fracturing fluid and the opening degree of each cluster of fractures, they provide a guarantee for the successful completion of fracturing operation and a reliable support for the optimization of fracturing process design.

\section{References}

1. Wu Xiaoling, Gao Bo, Ye Xin, Bian Ruikang, Nie Haikuan, Lu Fuzhang. Reservoir formation conditions and exploration potential of shale oil in the fault basin of eastern China $[\mathrm{J}]$, Oil and gas geology, 2013, 34(04): 455-462.

2. Zhou Lihong, Yu Chao, Hua Shuangjun, Sun Chaonan, Wang Na. Shale Oil Resource Estimation and Application in Kong2 Member of Cangdong Sag[J].Special Oil \& Gas Reservoirs, 2017, 24(06) : $1-6$.

3. Chen Shiyue, Hu Zhongya, Liu Wei, et al. Characteristics of shale and exploration potential of shale oil in Kong 2 Member of Jidong Depression[J]. Science Technology and Engineering, 2015,15(18):26-33.

4. Wang Wenguang, Lin Chengyan, Zheng Min, Lu Shuangfang, Wang Min, Zhang Tao.Sedimentary Characteristics of the Mudstone and Shale in the Second Member of Kongdian Formation in Cangdong Sag and Its Potentiality for Shale Oil[J].Science Technology and Engineering, 2018, 47(02): 332-344.

5. Lai Jin, Wang Guiwen, Fan Zhuoying, et al. Research progress on logging evaluation method for unconventional oil and gas reservoir brittleness index[J]. Petroleum Science Bulletin, 2016, 1(03): 330-341.

6. Zhao Yudong. Calculation of Brittleness Index Based on Logging Data[J]. Petrochemical Technology, 2017,24(09):285.

7. Wu Qi, Xu Yun, Zhang Shouliang, Wang Tengfei, Guan Baoshan, Wu Guotao et al. The core theories and key optimization designs of volume stimulation technology for unconventional reservoirs[J]. Acta Petrolei Sinica | Acta Petrol Sin, 2014, 35(4) : 706-714. 
8. Zhao Zhihong, Huang Chao, Guo Jianchun, Zhou Yuebo. Feasibility of complex fracture networks under simultaneous fracturing in shale reservoirs[J].Fault-Block Oil and Gas Field,2016, 23(5): 615-619.

9. Zhou Lihong, Yu Chao, Hua Shuangjun, Sun Chaonan, Wang Na. Shale Oil Resource Estimation and Application in Kong2 Member of Cangdong Sag[J].Special Oil \& Gas Reservoirs, 2017, 24(06): 1-6.

10. Zhou Lihong, Pu Xiugang, Han Wenzhong, Chen Zhangwei, Zhang Wei, Lin Changmei et al. Sedimentary characteristics and hydrocarbon exploration of Ek 2 of Nanpi slope area,Cangdong sag,Huanghua depression,North China[J].Journal of Chengdu University of Technology (Science \& Technology Edition), 2015, 42(05): 539-545.

11. Zhao Xianzheng, Zhao Pingqi, Li Dongping, Wu Xi, Wang Wenchang, Tang Shizhong. Research and practice of geology-engineering integration in the exploration and development of Dagang oilfield[J]. China Petroleum Exploration, 2018, 23(2): 6-14 